\title{
Queixa, demanda e desejo na clínica fonoaudiológica: um estudo de caso clínico
}

\section{Complaint, demand and wish in Speech-Language Pathology clinical practice: a case study}

\author{
Vanessa Ieto $^{1}$, Maria Claudia Cunha ${ }^{2}$
}

\begin{abstract}
RESUMO
A queixa é o primeiro momento de contato entre paciente e terapeuta e dirá sobre os conteúdos manifestos dos sintomas e sobre os conteúdos latentes relacionados a ela: a demanda e o desejo. O objetivo deste trabalho foi identificar, por meio de um estudo de caso clínico, de que modo o reconhecimento da existência de uma demanda e de elementos relacionados ao desejo, ambos subjacentes à queixa do paciente, podem orientar a condução do processo terapêutico fonoaudiológico desde a entrevista. O método utilizado foi o estudo longitudinal de um caso clínico de um paciente com 11 anos, do sexo masculino, atendido entre setembro/ 2003 e dezembro/2004, com a queixa enunciada pelo pai: "T. não fala, só se comunica por sinais". A interpretação do material clínico foi subsidiada pela articulação entre referenciais teóricos fonoaudiológicos e psicanalíticos. Esse estudo obedeceu às normas éticas estabelecidas para pesquisas com seres humanos. Os resultados apontaram que a demanda do paciente estava relacionada à necessidade de ser escutado pela família e o desejo caminhava em direção à manutenção do sintoma, como forma de assegurar a continuidade do investimento familiar. Tais conteúdos subsidiaram as intervenções terapêuticas que resultaram no aumento da oralidade de T., possibilidade de interlocução e reconfiguração das queixas familiares. A(s) entrevista(s) deve(m) preceder e subsidiar os processos terapêuticos fonoaudiológicos e a queixa deve ser escutada para além da literalidade. A introdução do desejo interdita o tradicional planejamento terapêutico prévio, pois os conteúdos psíquicos relacionados aos sintomas não se submetem e/ou podem ser obstaculizados por atividades pré-programadas.
\end{abstract}

Descritores: Fonoterapia; Distúrbios da fala/terapia; Criança

\section{INTRODUÇÃO}

A queixa é o primeiro momento de contato entre paciente (e/ou seus responsáveis) e terapeuta e diz respeito aos conteúdos manifestos e conscientes relacionados ao sintoma apresentado $^{(1)}$. É por seu intermédio que o paciente chega à clínica fonoaudiológica e formula um pedido de ajuda endereçado ao terapeuta: a demanda.

Desta forma, cabe à entrevista inicial um papel importante, pois ela deve configurar-se como um espaço de escuta e acolhimento, que favoreça que o paciente e/ou seus res-

Trabalho realizado na Pontifícia Universidade Católica de São Paulo - PUCSP - São Paulo (SP), Brasil.

(1) Mestre, Membro do grupo de pesquisa Distúrbios da Linguagem, Corpo e Psiquismo da Pontifícia Universidade Católica de São Paulo - PUC-SP São Paulo (SP), Brasil.

(2) Doutora, Professora Titular da Faculdade e do Programa de Estudos PósGraduados em Fonoaudiologia da Pontifícia Universidade Católica de São Paulo - PUC-SP - São Paulo (SP), Brasil.

Endereço para correspondência: Vanessa Ieto. R. Adrianópolis, 147, Tatuapé, São Paulo - SP, CEP:03324-070. E-mail: vanieto@ig.com.br

Recebido em: 22/3/2007; Aceito em: 13/7/2007 ponsáveis, além de enunciarem a queixa, falem também sobre o sofrimento relacionado a ela. Isto é, a respeito dos conteúdos latentes que permeiam o(s) sintoma(s). Nessa perspectiva, o trabalho das entrevistas preliminares pode fazer com que o sofrimento explícito ou implícito do entrevistado torne-se uma demanda de análise ${ }^{*}$ (2). Desta forma, a demanda seria a porta de entrada do paciente na clínica, quando este busca por meio de seus sintomas e sofrimentos, um projeto consciente de mudança ${ }^{(3)}$.

Segundo Freud, a força motivadora primária na terapia é o sofrimento do paciente e o desejo de ser curado que deste se origina ${ }^{(4)}$. Desse modo, o sofrimento seria o responsável pela procura de ajuda profissional e manteria o paciente em terapia a fim de decifrar seus enigmas.

A Psicanálise nos auxilia a compreender esse processo, a saber: o de escutar a demanda subjacente à queixa enuncia-

\footnotetext{
* O tema é amplamente tratado na bibliografia psicanalítica. Portanto, em algumas citações desse texto, aparecem os termos "análise" e "analista". Contudo, o leitor deverá considerar as possíveis aproximações com a fonoterapia.
} 
da, na medida em que nos alerta sobre a dinâmica psíquica envolvida nos modos peculiares pelos quais os sintomas se instalam e, consequientemente, os efeitos singulares que produzem no paciente e em sua família ${ }^{(5)}$.

Em outras palavras, o referencial teórico psicanalítico possibilita ao fonoaudiólogo escutar para além daquilo que é dito, assumindo a existência do sentido na alma da pala$v r a^{(6)}$, o que implica a não existência de um sentido unívoco, pleno e homogêneo.

Nessa perspectiva teórica, o sintoma deve ser compreendido para além de sua aparência, o que significa tomá-lo como a ponta de um iceberg; isto é, somente seu conteúdo manifesto (consciente) é visível. Contudo, no invisível, existem conteúdos latentes (inconscientes) que necessitam ser "decifrados" pelo terapeuta. Assim, a ponta do iceberg sugeriria um conteúdo submerso, somente acessível através de uma escuta terapêutica atenta, simultaneamente, àquilo que é dito e aos seus possíveis significados na rede de relações bio-psíquicas constituintes do sujeito ${ }^{(7)}$.

Explicitando: a noção de escuta assenta-se no pressuposto de que aquele que fala diz mais do que se propõe (literalmente), em decorrência de rompimentos com a lógica consciente $^{(8)}$. Por sua vez, todos esses conteúdos (ditos e não ditos) estão envolvidos no sofrimento que faz surgir uma demanda de ajuda, a qual leva um sujeito a procurar diversos profissionais, entre eles o fonoaudiólogo, em busca de alívio.

A assunção de tais pressupostos estabelece a relevância de se diferenciar queixa e demanda, que pode ser enunciada como se segue. A primeira define-se pela percepção consciente do sofrimento por parte do sujeito, enquanto a segunda impulsiona a procura de ajuda, implicando o sujeito na sua parcela de responsabilidade em relação ao sintoma e motivando, efetivamente, o vínculo terapêutico.

Por sua vez, o aprofundamento teórico dessas reflexões, sempre subsidiado pela literatura psicanalítica, faz emergir outro importante conceito: o desejo, elemento não enunciável, inconsciente, ligado a lembranças infantis indestrutíveis e que está na base de toda demanda ${ }^{(9)}$.

Assim, as considerações até aqui realizadas delineiam o objetivo deste trabalho: identificar, por meio de um estudo de caso, de que modo o reconhecimento da existência da demanda e de elementos relacionados ao desejo, ambos subjacentes à queixa do paciente, pode orientar a condução do processo terapêutico fonoaudiológico desde as entrevistas preliminares.

\section{APRESENTAÇÃO DO CASO CLÍNICO}

Este trabalho foi aprovado pela Comissão de Ética e Pesquisa da instituição em que foi realizado (protocolo número 0203/2003).

\section{História de T.}

O relato de caso refere-se a um menino (T.), nascido em 1992 e que, na época do início do atendimento fonoaudiológico, tinha 11 anos de idade. A primeira entrevista foi realizada com o pai.
T. nasceu prematuro (no sexto mês de gestação) e teve anóxia peri-natal. Desta condição foi diagnosticado um quadro de paralisia cerebral leve. Após o nascimento, foi necessária a sua internação hospitalar durante os primeiros três meses de vida. Após ter tido alta, T. teve convulsões que persistiram até os nove anos e foram controladas por medicamentos. Os exames clínicos neurológicos diagnosticaram alterações na atividade cerebral. Além disso, faz audiometrias anualmente por indicação do médico otorrinolaringologista, responsável pelo tratamento da sua rinite alérgica, e tais avaliações sempre apresentam resultados dentro dos padrões de normalidade.

Sobre a gravidez, o pai contou que T. havia sido muito desejado. No entanto, a mãe precisou submeter-se a diversos tratamentos médicos por alguns anos, pois não conseguia engravidar. Durante a gestação, ela apresentou hipertensão constante.

No relato do pai, pôde-se perceber seu investimento nos cuidados com o filho, dizendo que estava na fila de espera por uma vaga, no setor de fisioterapia de uma universidade e, também, para natação em um parque estadual, além do tratamento odontológico em curso.

Relatou, ainda, que T. havia desenvolvido uma comunicação basicamente por gestos, apesar da terapia fonoaudiológica anteriormente realizada, e que as únicas palavras produzidas pelo filho eram " $p e$ " para pai, "me" para mãe e " $a$ " para água.

\section{A enunciação da queixa}

T. já havia realizado terapia fonoaudiológica por volta dos seis anos de idade e a procura por um novo atendimento concretizou-se devido à seguinte queixa, enunciada pelo pai na entrevista inicial: Não entendo porque depois de quatro anos de tratamento de fono, T. não fala, só se comunica por gestos.

Devido ao fato da mãe não ter comparecido à entrevista inicial, ela foi chamada para uma nova entrevista e queixouse de que não compreendia o porquê de seu filho não falar e complementou, dizendo que ele não sabia fazer nada sozinho (como, por exemplo, alimentar-se e vestir-se).

\section{Sintomas manifestos}

Durante as primeiras sessões, foi marcante a compulsão de T. em organizar previamente as brincadeiras: abria o armário, selecionava e dispunha os objetos sobre a mesa; mas, efetivamente, não brincava. Parecia satisfazer-se em apenas deixar tudo na mais perfeita ordem. Esse comportamento se intensificava quando a terapeuta lhe comunicava que a sessão havia terminado: T. não conseguia ir embora, antes de deixar a sala exatamente do mesmo modo que a havia encontrado ao chegar e, com o mesmo rigor, guardava todos os objetos.

Esse, digamos "excesso", também se manifestava na sua aparência física: cabelos cuidadosamente penteados, roupas impecáveis, os óculos presos ao pescoço por uma corrente.

A linguagem oral era escassa. T. utilizava-se principal- 
mente de gestos como estratégia comunicativa e o fazia de forma eficiente, na maioria das vezes. Em algumas situações, os gestos eram acompanhados pela repetição das vogais "o" e "a", sem variações entonacionais. Neste início, era como se falar tivesse realmente o valor de arrancar uma parte dele mesmo ${ }^{(10)}$, ou seja, inicialmente, T. não ousava falar; havia uma inabilidade em estabelecer um vínculo por meio da fala. Seu silêncio representava uma forma de não interagir com o outro por intermédio das palavras.

Grafava seu nome e algumas letras. Reconhecia o alfabeto, grafando-o em seqüência quando solicitado a escrever algo, mas não lia.

\section{Processo terapêutico}

Durante os atendimentos foram usados jogos e brinquedos de encaixe, escolhidos pelo próprio paciente. Nessas situações, eram constantes as tentativas da terapeuta em atribuir significado àquilo que T. produzia oralmente. Por exemplo, durante um jogo, ele batia no peito e dizia "Co-Co", o que pôde ser interpretado como uma tentativa em dizer seu próprio nome. Diante disso, passou a referir-se a si próprio como "Co".

Em uma das sessões, foi realizado o preparo de massa de modelar, com a mistura de diversos ingredientes. Inicialmente, T. mostrou-se aflito por ver-se sujando as mãos. No entanto, passado esse desconforto inicial, lambuzou-se e colocou a mão na massa, prazerosamente, desistindo de qualquer tipo de controle; inclusive babando sobre a mistura. Esta passagem ilustra um dos primeiros efeitos terapêuticos sobre as condutas habituais do paciente.

Em um dos atendimentos, T. pegou um lápis e solicitou (por meio de gestos) um apontador. Disse-lhe que, naquele momento, não havia nenhum, mas que poderia trazer-lhe na sessão seguinte.

Pode-se dizer que isso se tornou um ritual, do qual T. parecia utilizar-se para assegurar-se de que os atendimentos teriam continuidade: ele pedia algo que não havia no armário de brinquedos e, na sessão seguinte, por meio de gestos, verificava se sua solicitação havia sido atendida.

Quanto ao sistema estomatognático, a avaliação foi realizada da seguinte forma: primeiro, ele poderia observar a minha região oral e depois seria a minha vez de observar a dele. Após uma longa negociação, deixou que eu o fizesse, mas logo desistiu, insistindo que eu guardasse todos os materiais. A partir daí, pôde-se perceber que as atividades que envolviam toques corporais (principalmente na região oral) eram rejeitadas por ele.

Na maioria das vezes, as atividades que T. recusava estavam ligadas a procedimentos relacionados à motricidade oral. Contudo, por intermédio da observação desse aspecto, pôdese perceber uma hipotonia da musculatura facial, lábios e língua, dificultando o vedamento labial. Além disso, observou-se uma diminuição da propiocepção da região intra-oral, sialorréia constante e estavam presentes dificuldades práxicas, associadas ao quadro lesional.

Em uma das sessões, propus a T. que adivinhasse, com os olhos fechados, o alimento que seria colocado em sua boca.
Inicialmente, ele o recusou, como nas outras sessões. Mas, diante de um novo pedido e de minha intervenção, dizendo que sabia que ele não gostava que eu mexesse em sua boca, e que essa atividade não seria desprazerosa, ele acabou cedendo.

O objetivo daquela atividade era trabalhar a propriocepção da região oral, que parecia adormecida. Freqüentemente, T. babava, não tendo nenhum controle sobre a salivação. Além disso, sua articulação era bastante precária, isto é, sua fala restringia-se a sílabas compostas por vogais e consoantes oclusivas bilabiais como " $p a$ " e " $m a$ ". Quando propunha que ele tentasse dizer outras palavras, cuja estrutura fonológica fosse mais complexa, recusava-se e batia na cabeça, como se dissesse que sua dificuldade em falar era devido a um problema na cabeça.

Gradativamente, T. passou a envolver-se intensamente nas atividades de propiocepção oral, até que, certo dia, ao entrar na sala, direcionou a mim, pela primeira vez, uma palavra sem qualquer alteração lingüística: "liga", (solicitando que eu ligasse o computador). Avaliei que se estabelecia uma coocorrência importante entre as atividades motoras orais e a emergência da linguagem oral.

\section{A construção de demandas}

Desde as primeiras sessões, pôde-se perceber a construção de uma demanda endereçada à terapeuta: T. precisava ser escutado. Suas escassas tentativas de falar não eram acolhidas pelos pais como linguagem. Assim, não lhes era possível tomá-lo como um interlocutor, o que parecia relacionado a uma perpetuação das circunstâncias patologizantes que o cercaram desde o nascimento.

Durante o processo terapêutico, outras sessões foram realizadas com os pais com o objetivo de que pudessem retomar/ elaborar a história de vida do filho. $\mathrm{O}$ pai destacou o fato de que, após o nascimento, T. permaneceu na UTI neonatal, por volta de três meses, cheio de tubos e fios ligados a ele... era muito pequeno, cabia na palma da mão. Após ganhar peso, recebeu alta do hospital e foi para casa. No entanto, devido aos freqüentes episódios de convulsão, foram necessárias diversas internações hospitalares subseqüientes.

A mãe também contou que, muitas vezes, ela o observava brincando sozinho e falando, mas, ao perceber que alguém o olhava, calava-se. Diante disso, pode-se levantar a hipótese de que existia uma percepção por parte de T. do investimento que os pais faziam em seus sintomas e, talvez, isso o aprisionasse nessa rede sintomatológica, fazendo com que, por exemplo, falasse somente quando não lhe era lançado um olhar patologizante.

Portanto, no caso de T., os acontecimentos ocorridos relacionados ao nascimento prematuro, seguidos das internações hospitalares subseqüentes, podem ter gerado esse efeito nos pais: a ausência de escuta e olhar para suas possíveis evoluções.

Também desde os primeiros atendimentos, T. pouco usava a linguagem oral, mas suas estratégias comunicativas alternativas (como o uso de gestos) faziam com que ele pudesse ser compreendido. No entanto, existiam algumas situa- 
ções em que isso não ocorria e, em tais contextos, após serem dadas interpretações sobre possíveis sentidos, quando a terapeuta "acertava", ele passava a olhar fixamente para sua boca, como se quisesse copiar aquele ato motor.

Certa vez, diante do computador, T. vocalizou "co-coco". Questionado se queria ir ao banheiro para fazer cocô, começou a gargalhar, apontando para o computador. Então, disse-lhe que havia compreendido que estava se referindo ao computador e não ao cocô, mas que o modo como ele havia falado inicialmente, fez com que eu me confundisse. Assim, ele fixou seu olhar em minha boca e tentou realizar o mesmo gesto motor, tentando dizer computador. O resultado foi uma emissão semelhante a "couaô".

Em uma conversa subseqüente com o pai, este atribuiu a um milagre o fato de T. ter sobrevivido e explicou que T. só começou a andar de tanto que foi forçado, dizendo: pegava na mãozinha dele todos os dias e o fazia andar. Não se pode negar que os investimentos paternos foram fundamentais para o desenvolvimento do paciente, mas o que estaria inviabilizando a fluência da fala?

\section{Uma possibilidade de acesso ao desejo}

$\mathrm{O}$ desejo de T. parecia caminhar em direção à manutenção do sintoma de linguagem, talvez como forma de assegurar a continuidade do investimento familiar. Porém, na medida em que o investimento dos pais começou a ir para outra direção, digamos "despatologizante", começou a ser possível uma intervenção terapêutica mais efetiva. Um exemplo dessa conduta paterna ocorreu em uma das sessões em que T. chegou com o cabelo raspado. Quando perguntei sobre o novo penteado, T. disse "Guga", o que o pai completou que T. quis cortar o cabelo como o jogador de tênis (Guga). Esta foi a primeira vez que presenciei o fato de T. ser interpretado pelo pai.

É importante salientar o fato dos pais retomarem a procura pelo atendimento fonoaudiológico na entrada de T. na adolescência. Em uma de nossas conversas, a mãe enunciou que gostaria que T. começasse a se virar sozinho, pois eles (os pais) não durariam para sempre e ele teria que se explicar sem ajuda.

Parece iniciar-se aí um movimento diferente na dinâmica familiar: a mãe começa a perceber que não poderia cuidar de T. eternamente e, então, vai se intensificando o processo de despatologização, com vistas a alguma autonomia.

\section{A reconfiguração das queixas familiares}

Foi somente pelo reconhecimento das potencialidades de T., apesar do seu desejo insistente de manutenção do sintoma, que a linguagem oral do paciente pôde emergir no setting; desencadeando, no pai, a seguinte afirmação: mas, aí dentro, com você, ele fala tanto!

No início dos atendimentos, T. utilizava principalmente gestos para se comunicar, apontando aquilo que desejava. Contudo, no decorrer das atividades lúdicas (por exemplo: "fazer comida"), foi sendo possível inserir o paciente em um contexto dialógico, no qual as produções orais compostas principalmente por vogais como "o" (para chocolate) e "a" (para água) foram tomando outras formas lingüísticas. Por exemplo, quando apontava a caixinha de leite e dizia "e", imediatamente a intervenção era dizer a palavra completa, "leite", ao que T. fixava o olhar em minha boca, como se copiasse o gesto motor e, na sequiência, dizia "eie".

Em determinado momento do processo terapêutico, $\mathrm{T}$. passou a ser levado aos atendimentos somente por sua mãe. Embora a justificativa para tal fato fosse uma incompatibilidade de horário do pai, tal fato também pôde ser interpretado como uma evolução, já que durante os primeiros tempos de atendimento, a mãe ficava à margem do processo. Finalmente, parece emergir, de maneira mais efetiva, a figura materna, inclusive reconhecendo a potencialidade do filho: "ele já está tomando banho e se trocando sozinho. Demora, mas já está conseguindo fazer sozinho”.

Além disso, pôde-se notar uma reconfiguração da queixa inicial. O pai agora enunciava: T. fala pouco (sic). Já a mãe afirmava que gostaria que o filho falasse direito. Essas mudanças no discurso parental em relação à queixa inicial (ausência de fala) foram substituídas por pouca fala e fala incorreta e podem ser interpretadas como o modo que eles encontraram para dizer que seu filho estava evoluindo.

\section{DISCUSSÃO}

Nesse estudo de caso, assume-se a postura do fonoaudiólogo como intérprete ${ }^{(11)}$, que além de ouvir, mantém a escuta atenta, de maneira a intervir nos conflitos bio-psíquicos envolvidos nos sintomas manifestos pelo paciente.

Ao migrar para o campo fonoaudiológico, o conceito de demanda carece de reflexão: é necessário avaliar se a clínica fonoaudiológica consegue apreendê-la em meio a queixas tão especificamente centradas nos sintomas manifestos.

No caso apresentado, pode-se atribuir um papel fundamental às entrevistas realizadas com os pais de T. Este procedimento inicial permitiu que eles enunciassem uma queixa endereçada ao fonoaudiólogo, mas também trouxessem suas versões sobre a(s) história(s) relacionadas a ela: a prematuridade e internações subseqüentes de T. e o sofrimento familiar em tais circunstâncias.

Assim, a demanda pode começar a ser apreendida nas entrevistas preliminares. Já, os conteúdos relativos ao desejo foram sendo vislumbrados no decorrer do processo terapêutico.

Constatou-se que T. possuía capacidade articulatória para expressar-se oralmente, porém, na relação com o outro, tinha dificuldades para assumir a posição de interlocutor verbal-oral.

Em relação às possíveis causas do distúrbio fonológico, pode ser encontrada uma grande diversidade de autores que o relacionam a fatores como sexo, idade, ocorrência de otite, processamento auditivo e também ao aspecto familiar ${ }^{(12)}$. Nesse estudo, o paciente era portador de uma lesão cerebral decorrente da anóxia de parto e disso resultou um quadro de paralisia cerebral leve. Este quadro clínico sugere uma dificuldade em relação à praxia. Contudo, a partir do momento em que o paciente passou a ser escutado e que o conteúdo do 
seu discurso (embora precário lingüisticamente) passou a ser interpretado, ocorreu uma melhora qualitativa e quantitativa em relação à oralidade.

Portanto, existe uma grande complexidade de fatores que regem as dificuldades apresentadas por T., como os aspectos orgânicos relacionados à sua condição. No entanto, o paciente convoca o fonoaudiólogo a refletir sobre os sintomas de modos singulares ${ }^{(13)}$, o que possibilitou a apreensão da demanda endereçada à terapeuta, que foi a de que T. precisava ser escutado e reconhecido, para além das circunstâncias patologizantes que o marcaram desde o nascimento.

Em síntese, a demanda que o paciente endereça ao fonoaudiólogo está engendrada pelos conteúdos latentes relacionados ao desejo, e ambos (demanda e desejo) subjazem a uma queixa específica.

No caso de T., o reconhecimento de elementos relativos ao desejo de manutenção do sintoma (possivelmente, por temer a perda dos cuidados familiares) fez com que as interpretações se tornassem mais efetivas. Na medida em que $\mathrm{T}$. pôde se reconhecer no setting como sujeito de suas potencialidades, a linguagem oral evoluiu quantitativa e qualitativamente.

Com isso, sugere-se que a possibilidade de acesso ao desejo torna-se questão para a Fonoaudiologia, na medida em que o reconhecimento desta instância está relacionado à efetividade dos processos terapêuticos.

\section{COMENTÁRIOS FINAIS}

Dizer que aquilo de que o paciente (e/ou responsáveis) se queixa convoca uma escuta terapêutica para além da literalidade, já que abriga desejos inconscientes; reconfigura aspectos importantes do método clínico-terapêutico fonoaudiológico, sugerindo: 1. A pertinência das entrevistas preliminares; 2. A inviabilidade do planejamento terapêutico prévio.
Explicitando:

1. As entrevistas preliminares devem preceder e subsidiar os processos terapêuticos fonoaudiológicos, seja qual for a queixa enunciada, pois permitem que as representações subjetivas relacionadas ao sintoma possam ser expressas. Ao chegar à clínica, o paciente e/ou familiares falam sobre aquilo que pode ser dito mais facilmente: a queixa, um enunciado consciente. Já, os conteúdos inconscientes nela envolvidos constituem a demanda e o desejo. Trata-se, portanto, de ouvir a queixa e conduzir a(s) entrevista(s) a partir das versões do paciente e/ou familiares sobre o sofrimento relacionado ao sintoma.

Isso significa que a queixa tem de ser ouvida, pois ela dirá sobre a representação que o paciente e/ou familiares fazem de seu próprio sintoma. Contudo, é fundamental que se escute para além desse enunciado.

Portanto, procedimentos como a anamnese, isto é, um conjunto de perguntas pré-estabelecidas que visam conhecer exaustivamente a doença e suas possíveis causas, tornam-se inadequados, pois obstruem essa escuta terapêutica.

2. Na seqüência, durante o processo terapêutico, pode ocorrer a reconfiguração da queixa, surgindo elementos relativos ao desejo, na medida em que o terapeuta abra espaço para que estes venham à tona.

A introdução deste terceiro elemento (o desejo) interdita o tradicional planejamento terapêutico prévio, pois lidar com elementos relativos ao desejo significa considerar a dimensão inconsciente relacionada ao sintoma, a qual não se submete a atividades pré-programadas.

Embora o desejo não seja objeto de intervenção terapêutica do fonoaudiólogo, considerar sua existência amplia as possibilidades de interpretação e ressignificação do sintoma.

Em síntese, durante o processo terapêutico, o fonoaudiólogo deve acolher queixa, demanda e desejo, no sentido de tornar os processos terapêuticos mais efetivos.

\begin{abstract}
The complaint is the first contact between pacient and therapist and will provide information about the symptoms and their features. It will also provide data about related subjective issues: demand and wish. The purpose of this paper is to identify, through a case study, how the acknowledgment of wish and demand underlying the subject's explicit complaint can determine the course of the speech-language-therapy process since the first interview. The method was a follow-up study of an 11-year-old boy attending speechlanguage therapy from September 2003 to December 2004. The father's explicit complaint was “T doesn't talk he only communicates through signals". The interpretation of the clinical data was supported by the theoretical speech-and-language-pathology and psychoanalytical frameworks. This study followed ethical procedures determined for research with human beings. Results point out that the patient's demand was related to his need of being heard by his family. On the other hand, his wishes were directed towards the maintenance of the symptoms as a way of securing the continuity of the family's attention. Such information provided the background to the therapeutic intervention that resulted in an improvement of the child's oral utterances and communicative exchange alternatives, reshaping the family's complaints. The interviews should precede and support the speech-language therapy processes and the complaints should be considered beyond its literal meaning. The unspoken wish may interdict planned therapeutic processes because psychic contents related to the symptoms cannot be controlled by pre-programmed activities.
\end{abstract}

Keywords: Speech therapy; Speech disorders/therapy; Child 


\section{REFERÊNCIAS}

1. Cunha MC. Fonoaudiologia e psicanálise: a fronteira como território. São Paulo: Plexus; 1997.

2. Rocha FJB. Do pedido de ajuda à demanda de análise: sobre escuta psicanalítica e entrevistas preliminares. Rev Alter. 2000;19(1):29-41.

3. Rocha F. Algumas considerações sobre as entrevistas preliminares, demanda e início de análise. Percurso. 1991;3(5/6):15-21.

4. Freud S. Sobre o início do tratamento. (1913). Rio de Janeiro: Imago; 1969. v.12. [Edição Standard Brasileira das Obras Psicológicas Completas].

5. Ieto V, Kelly REOG. Olha para mim... A gagueira como demanda de reconhecimento no espaço familiar. Distúrb Comun. 2003;14(2):36177.

6. Palladino RRR. Repetir a palavra alheia, ou de como refletir sobre esse sintoma na companhia da psicanálise. Rev Latinoam Psicopatol Fundam. 1999;2(1):90-106.
7. Tassinari MI. Objetividade e subjetividade nos processos terapêuticos fonoaudiológicos. Distúrb Comun. 2000;12(1):75-90.

8. Alonso SL. A escuta psicanalítica. Percurso. 1988;1(1):20-3.

9. Kupfer MCM. Desejo de saber [tese]. São Paulo: Instituto de Psicologia da Universidade de São Paulo; 1990.

10. Golse B, Guinot M. La bouche et l'oralité. Rééduc Orthophon. 2004;42(220):23-30.

11. Cunha MC. Desesquecimento: sobre a escolha do material clínico na pesquisa fonoaudiológica. Distúrb Comun. 2000;12(1):91-9.

12. Wertzner HF. Fonologia: desenvolvimento e alterações. In: Ferreira LP, Befi-Lopes DM, Limongi SCO, organizadores. Tratado de fonoaudiologia. São Paulo: Roca; 2004. p. 772-86.

13. Bom RBP, Cunha MC. Terapia fonoaudiológica com pacientes adultos: um estudo de caso. Rev Soc Bras Fonoaudiol. 2006;11(1):37-42. 